\title{
Urban or Rural GP? In the Czech Republic It Is not just Distances That Matter
}

\author{
Jan Bělobrádek ${ }^{1,3, *}$, Luděk Šídlo², Kateřina Javorskái, ${ }^{3}$, David Halata ${ }^{3}$
}

\begin{abstract}
This article proposes a combined mixed methods approach to categorising GP practices. It looks not only at location but also at differences in the nature of the work that rural GPs perform.

A data analysis was conducted of the largest health insurance company in the Czech Republic (5.9 million patients, $60 \%$ of the population, $100 \%$ coverage within the Czech Republic). We performed two data analyses, one for 2014-2015 and one for 2016, and divided GP practices into urban, intermediate, and rural groups (taking into account the OECD methodology). We compared groups in terms of the total annual cost in CZK per adult registered insurance holders. The total volume of data indicated the financial costs of $€ 1.52$ billion and $€ 2.57$ billion respectively.

Both analysis showed differences between all groups of practises which confirmed the assumption that the work of the GP is influenced by regionality. A multidisciplinary hospital is the main factor that fundamentally affects the way a GP's work in that area.

The proposed principle of categorising general practices combines geographical and cost characteristics. This requires knowledge of the cost data of healthcare payer and on the basic demographic knowledge of the area. We suggest this principe may be transferrable and particularly suitable for categorising general practice.
\end{abstract}

\section{KEYWORDS}

general practice; rural health; regional typology; workforce; efficiency

AUTHOR AFFILIATIONS

${ }^{1}$ Department of Preventive Medicine, Charles University, Faculty of Medicine in Hradec Králové and University Hospital Hradec Králové, Czech Republic

${ }^{2}$ Department of Demography and Geodemography, Charles University, Faculty of Science, Prague, Czech Republic

${ }^{3}$ Working Group on Rural Practise of the Czech GP Society, Czech Republic

* Corresponding author: Charles University, Faculty of Medicine in Hradec Králové, Department of Preventive Medicine, Hradec Králové, Czech Republic; mudrjanbelobradek@gmail.com

Received: 9 August 2020

Accepted: 4 December 2020

Published online: 14 April 2021

Acta Medica (Hradec Králové) 2021; 64(1): 15-21

https://doi.org/10.14712/18059694.2021.3

(c) 2021 The Authors. This is an open-access article distributed under the terms of the Creative Commons Attribution License (http://creativecommons.org/licenses/by/4.0), which permits unrestricted use, distribution, and reproduction in any medium, provided the original author and source are credited. 


\section{INTRODUCTION}

The issue of the division of territory into urban and rural one is a typical multidisciplinary topic, discussed in many disciplines - geography, demography, sociology, economics, etc. In many regions it is also a key social and political topic, especially in connection with urbanization trends that can be observed worldwide, regardless of the size, political or economic characteristics of the continent or state.

Difficulty of distinguishing rural GP practices is also a global topic that has attracted much research in all parts of the world (1-4). This is true regardless of the distribution in the given country, its economic level or used healthcare system. The key issues are how a given territory should be divided (definition of rural areas) (5-7), the equity in healthcare access (8-10), the specific nature of rural general practice (11-13), and long-term sustainability in the face of increasing urbanisation (14-16).

It might seem that a smaller area is an advantage, especially if it is a geographically homogeneous state in a stable socio-economic environment of the EU. Nevertheless, even a small Central European country such as the Czech Republic does not avoid the typical problems of rural medicine. Like elsewhere, doctors in the Czech Republic tend to prefer working in towns or cities (17). The increasing difficulty of finding medical staff for rural practices is an important local policy issue that is gradually becoming a strategic national issue (as part of the ongoing primary healthcare reforms instituted by the Czech Ministry of Health) (18).

Support for rural practices at many levels is being considered. Whether in the form of a direct financial incentive for doctors themselves (central or organized by the regional government), subsidies for the establishment, equipment and operation of practices, bonus mechanisms paid by health insurance companies, housing support (renting a municipal apartment or offering land to build a house) or supporting families of doctors (job opportunities for partners and children's education).

However, if similar support for rural practices was to exist, those practices must be properly defined (19). This is the only way how the transparency of the system, its sustainability and the minimization of clientelistic and corrupt influences are possible. In a country with a small area and a high number of healthcare providers, such as the Czech Republic is, it is not possible to rely only on geographical criteria. Compared to large countries, the distances here are short, nevertheless there is an outflow of workforce from rural areas. The question is, how it is possible to help with more precise determination of the borders between rural and urban areas? Other rural GP characteristics must also be taken into account (20).

Therefore, we decided on a combination of criteria: location and practice characteristics data, expressed in costs. In terms of regionality, we have created our own model of division of practices, which meets the conditions of the Czech Republic and takes into account the local health care system. We obtained not only cost data from the payer of the care, but also structure information of services that the payer reimburses for individual practices. We examined the extent to which the structure of GP activities is related to regionality and whether cost effectiveness or some of its components could be a suitable determinant for rurality in primary care.

The Czech Republic has currently the system of funding based on the general health care insurance $(21,22)$. Its health insurance companies not only pay for the care but are legally responsible for creating and maintaining the network of providers. The largest healthcare insurance company is the General Health Insurance Company (GHIC), which ensures 5.9 million patients (4.5 million adults) receive care. That is roughly $60 \%$ of the population. GHIC contracts cover almost $100 \%$ of the country and all healthcare service providers who are reimbursed through the public health insurance system (23).

The data held by the GHIC has been gradually made available for our research since 2016. The original intention was to monitor the differences between individual GP practices according to two criteria: 1 . the size of the practice, ie. according to the number of registered patients, 2. the location, ie. location in the city or in the countryside. As the first results already showed that the differences according to the first criterion (size of practice) are insignificant, we continued to focus only on the second criterion (location of practice).

The Czech Republic has a capitation performance-based model of payments. Capitation performance-based model of payments - a lump sum payment for a registered insured person, the amount of which increases with the patient's age, is used in the Czech Republic. The basic performance package is reimbursed through capitation, while technical procedures and prevention are reimbursed separately (insurance company payments are made based on the actual procedures performed according to a catalogue of prices). Depending on the fulfilment of predetermined criteria (e.g. number of preventive examinations, tests for occult bleeding, influenza and other vaccinations, etc.), bonus supplements are also paid.

\section{MATERIAL AND METHODS}

The first research was conducted using data from 2014-2015. We investigated the differences in relation to the size of the pacient's list (total number of registered patients) and location of practice (urban or rural). The variables were a production of data (financial costs of GP activities - their procedures, ancillary services, specialist care, home care, and prescriptions). We compared the total annual costs in CZK per adult, that is, per "unit insurance holder" (registered insurance holders calculated using age indexation). This measure is comprehensive, enshrined in care reimbursement agreements and is generally accepted. Its aim is to prevent the disadvantage of age at registration (for example, a patient in the age of 20, GP will receive 0.9 times the capitation payment, for a patient in the age of 802.9 times the capitation payment). With regard to the age structure of the population in the Czech Republic, the number of unit insurance holders exceeds the number of registered insurance holders.

The basic criterion for defining location of the general practice was the presence of a multispecialty hospital. 
According to the OECD method for defining territorial units we placed practices into three groups. We defined urban practices located in a town/city with a large hospital or near a town/city with a large hospital, where the catchment area was $5 \mathrm{~km}$ from the centre of the town/city (Type I). Usually these were GP practices in towns/cities with over 30,000 inhabitants and the remainder were all district towns (LAU 1 administrative centres). The intermediate group (Type II) comprised municipalities with extended state administration powers, where there are often smaller hospitals, and a catchment area of $10 \mathrm{~km}$. The remaining areas were categorised as rural (Type III). The total number of practices (FIDs - facility ID number) does not take into account the number of hours the doctor works nor the corresponding practice hours.

The results of the above described analysis has not only generated interest in further research but led to the founding of the Working Group on Rural Practise of the Czech GP Society (24) in 2016. Nonetheless, the investigators recognised that the research methodology could be improved. A further analysis was therefore conducted, using data from 2016. The aim of this research was to investigate regional differenties between GP. The focus was on two areas: 1. Improving the accuracy of the selection of the categories, bearing in mind the OECD regional typology criteria (Table 1) $(25,26)$; and 2. using as wide a range of data as possible. The data was structured in the same way, updated for 2016, and included data on bonus programme payments (training, programme quality). Particular attention was paid to procedures performed directly within GP practices.

We also changed the way to establish the total number of providers because most of the data was provided by the GHIC relating to GP practices as whole providers (PIDs - provider ID number). There are many practices in the Czech Republic in which a doctor is only available for a limited time. These are, for example, situations where the GP from the city arrives some afternoon to work from the adjacent village. This separate unit cannot be considered as a full-fledged practice, especially with regard to its costs. When determining the location of a given PID number, we relied on a longer working time for the doctor.

It was found that there are acute care hospitals in many of the Type II towns, which was the reason why the Type II was divided further into two groups - Type IIa - is a town with an acute care hospital in at least one of the basic specialisation (internal, surgery, paediatrics, gynaecology), and Type IIb refers to a town with no such hospital. We also added Type IV - a corporate, where the nature of the practice is different (a larger company generally consisting of a number of GP practices working closely with doctors from various specialties and a large laboratory, operating either at the local or the national level and a large number of commercial activities). Type $V$ refers to special general practices - military, prisons (Table 2).

\section{RESULTS}

\section{DATA ANALYSIS}

The initial analysis of the 2014-2015 data indicated that performance did not substantially differ in the size of the list of registered patients. In the Czech Republic the number of patients registered with a GP is determined by the capacity of the practice to provide the prerequisite care. However, practice location did have a marked effect on performance.

The costs of rural practices were lower (type III, total costs in the monitored variables lower by 7.3\%) in comparison with urban practices (type I). The same was true for intermediate practices (type II, total costs in monitored variables lower by $5.9 \%$ ). For some variables the difference was almost $30 \%$ (Table 3, Table 4).

Although the GHIC data sources were slightly different and types II and III changed parametrically, the conclusions regarding the 2016 data analysis were similar. Rural practices still had lower costs (Type III, total costs were $4.5 \%$ lower for the variables observed), the difference was more marked in relation to the intermediate practices (Type II, total costs were $7.2 \%$ lower for the variables observed) than urban ones (Type I). The largest differences in the variables were slightly over $30 \%$ (Table 3 , Table 4 ).

Tab. 1 Distribution of Czech population in 2016 according to OECD regional typology (in \%).

\begin{tabular}{|l|l|l|l|}
\hline OECD 2016 & $\begin{array}{l}\text { Predominantly } \\
\text { urban (PU) }\end{array}$ & $\begin{array}{l}\text { Intermediate } \\
\text { (IN) }\end{array}$ & $\begin{array}{l}\text { Predominantly } \\
\text { rural (PR) }\end{array}$ \\
\hline $\begin{array}{l}\text { Czech } \\
\text { Republic }\end{array}$ & 24.2 & 42.9 & 32.9 \\
\hline
\end{tabular}

Note: based on data on number of inhabitants in the Czech Republic in 2014 Source: 29,30

Tab. 2 Distribution of number of practices (FIDs in 2014-2015), and number of GP providers (PIDs in 2016) by type of region.

\begin{tabular}{|c|c|c|c|c|c|c|c|c|c|}
\hline \multicolumn{2}{|c|}{ Period (level) } & \multirow{2}{*}{$\begin{array}{l}\text { PU } \\
\text { Type I }\end{array}$} & \multicolumn{3}{|l|}{ IN } & \multirow{2}{*}{$\begin{array}{l}\text { PR } \\
\text { Type III }\end{array}$} & \multicolumn{2}{|l|}{ Other } & \multirow[t]{2}{*}{ Total } \\
\hline & & & Type II & Type Ila & Type Ilb & & Type IV & Type V & \\
\hline \multirow{2}{*}{$\begin{array}{l}2014-2015 \\
\text { (FIDs) }\end{array}$} & abs. & 3021 & 1907 & - & - & 477 & - & - & 5405 \\
\hline & $\%$ & 55.9 & 35.3 & - & - & 8.8 & - & - & 100 \\
\hline \multirow{2}{*}{$\begin{array}{l}2016 \\
\text { (PIDs) }\end{array}$} & abs. & 2349 & 758 & 246 & 512 & 1389 & 49 & 41 & 4586 \\
\hline & $\%$ & 51.2 & 16.5 & 5.4 & 11.2 & 30.3 & 1.1 & 0.9 & 100 \\
\hline
\end{tabular}

Source: authors' calculations 
Tab. 3 Basic GHIC input data (analyses for 2014-2015 and 2016).

\begin{tabular}{|l|l|l|}
\hline & $2014-2015$ & 2016 \\
\hline FIDs (practices) & 5405 & 4586 \\
\hline PIDs (providers) & & 4689.8 \\
\hline Number of registered insurance holders (in thousands) & 4462.7 & 6864.6 \\
\hline Number of unit insurance holders (age indexed) (in thousands) & 6480.7 & 2567.2 \\
\hline Total financial resources analysed (million EUR/year) & 1516.9 & 547.4 \\
\hline Analysed costs per registered insurance holder (EUR/year) & 339.9 & 374.0 \\
\hline Analysed costs per unit insurance holder (EUR/year) & 234.1 & \\
\hline
\end{tabular}

Source: GHIC

Tab. 4 Basic results of both analyses - differences in costs between types of practice by location (in \%).

\begin{tabular}{|c|c|c|c|c|}
\hline \multirow[t]{2}{*}{ Selected data cycles } & Type II/Type I & Type III/Type I & Type II/Type I & Type III/Type I \\
\hline & \multicolumn{2}{|c|}{ 2014-15 (difference in \%) } & \multicolumn{2}{|c|}{2016 (difference in \%) } \\
\hline Capitation & -0.1 & -2.9 & 0.0 & 0.1 \\
\hline Procedures & 13.0 & 23.6 & 6.5 & 18.3 \\
\hline Specialists - in total & -11.8 & -13.4 & -13.5 & -10.5 \\
\hline Ancillary services - in total & -19.1 & -23.9 & -10.4 & -8.3 \\
\hline Prescriptions - own & 24.4 & 29.8 & 17.7 & 32.2 \\
\hline Prescriptions - others & -7.4 & -9.8 & -5.1 & -6.3 \\
\hline Total (complete analyses) & -5.9 & -7.3 & -7.2 & -4.5 \\
\hline
\end{tabular}

Source: GHIC, authors' calculations

\section{DISCUSSION}

The results of the two analyses show that the differences mainly concern the nature of the activities and skill set of rural GP practices. These are influenced by conditions within the local healthcare system, as is the case at the global level too (rural general practices all over the world are forced to adapt to their environments). Information of this kind, frequently published, based on data provided by the GP practices themselves (in questionnaires or interviews) $(11-13,20)$. However, there is still very little published in the literature on the verification of costs to the payer in relation to primary care $(27,28)$. Similar characteristics are shown by doctors from smaller towns, although there are usually a larger number of GP's offices in them. Therefore, the crucial factor is the distance from the regional centre with the hospital, which has a decisive influence on the equipment of practices and the range of services performed.

The Czech Republic has an unusually high number of patient contacts with the healthcare system (29). This is reflected in the large number of hospital beds and associated longer than average hospital stays compared with other OECD countries (30), as well as in the larger number of specialists (31). The distribution of GP practices in the Czech Republic is also one of the most unequal, with most specialists providing care in larger towns and cities (32). This of course has had an effect on GP practices as well. While the care for patients registered with urban GP practices is also provided by hospitals and specialists (patients frequently seek out these services themselves, as gatekeeping is minimal), these options are limited in rural practices and so they provide more of the care themselves.

It is obvious that the determined absolute amounts of funds are influenced by the setting of the local health care system. The setting of the amount of capitation and the amount for individual services affect the total costs that are specific to the Czech Republic in a given period. Relative differences between different groups of practices are more important for further research or research in other regions.

In terms of spectrum of activity, rural GPs around the world are forced to adapt to the environment in which they operate. Globally, GPs cannot ignore performances for which they receive remuneration and are rewarded. Although it can be assumed that the amount of reimbursement affects the range of services, the advantage in our analysis is the inclusion of total costs of practices. This minimizes the possibility of distorting the results, because 
of the preference of a certain activity, which the payer placed more emphasis in the given period.

The costs of the GP segment used here (calculated as capitation per insurance holder) are not the same as the overall costs per head when calculated using the SHA methodology (A System of Health Accounts 2011) (33). In that system, all the costs of the healthcare system are calculated and the figure for the Czech Republic is $€ 1,850$ PPP (22). Our analyses were based only on the controllable GP costs relating to healthcare activities, paid for out of health insurance.

It is also necessary, to mention the similarity in the determination of the rural area in the case of results from the 2016 analysis and data published by the OECD. Our analysis considers $30.3 \%$ of GP practices to be rural; the OECD reports $32.9 \%$ of the population living in a predominantly rural area. We paid high attention to determining the degree of agreement between our methodology and the OECD methodology. This will be the topic of a separate publication.

In categorising the GP practices in the 2016 analysis, several variants were produced that were then compared with the OECD regional typology method. It uses the NUTS 3 level. We opted for a much more detailed image (municipalities with extended powers, a regional category used in the Czech Republic that is somewhere between LAU 1 and LAU 2), as it is better suited to distinguish between GP practices. However, differences in choice of method had no effect on categorising non-urban practices as intermediate and rural. What is important, though, is accurately defining urban practices (over $90 \%$ of which corresponded in all variants). These are the urban GP practices where we can best define the differences in the nature of the activities and thereby cost efficiency.

The practice included in the intermediate group seems to be interesting and promising for further research. This is a relatively heterogeneous group, for which other methods of division can be proposed. These practices operate in smaller towns, where there was usually a local hospital in the past. This created a network of related specialists. In some of these settlements, the hospital is still in operation, elsewhere its activities have been reduced to varying degrees, but often the hospital has been completely closed down (or transformed from acute hospital care to follow-up or social care). Cost data shows the highest efficiency of GP practices in the intermediate group. It can be explained by the optimal setting of the system, where more GPs and an adequate network of outpatient specialists operate in the given headquarters, but the easy path of patients to the necessary examination in a multidisciplinary hospital is hindered by a certain distance.

Multispecialty hospitals are more commonly used as a research variable in relation to access to care, than in relation to the patient, in rural medicine (19). But when considering the assessment criteria used in Central Europe, distance from the hospital or acute care unit is not as important (it is above the global standards) as the range of healthcare services available. This is because general practices operating in areas with a multispecialty hospital have a significant advantage in that the patient load can be shared more easily than is the case for their colleagues in small towns or rural areas. In the Czech Republic, the percentage of typical urban practices accounts for more than $50 \%$.

The involvement of the evaluation of GP cost effectiveness as a determinant of the division of practices is possible only with the knowledge of the data of the health care payer. Data from health insurance companies can be used in the Bismarck system. However, in any health care system based on the dominant role of the state in the organization and reimbursement of health care, there are payers who collect performance data. These are therefore available, which makes our model transferable and applicable in other regions, regardless of the type of health system. It is very suitable for the GP segment, which provides a wide range of care for the entire population, not just a selective sample of patients.

Our principle of territorial division is a combined principle, because it helps to divide practices into urban and rural by means of two different, complementary criteria. In a situation, where we are working shorter distances in Central Europe, we are solving the same problem with the lack of medical staff on the periphery as other countries. Only by distance, or another simple geographical or geomorphological criterion, our problems cannot be sufficiently explained. It is a functional principle, because there are no problems with the exact definition of rural areas. Explaining this problem will be more difficult for researchers than answering the questions they originally wanted to answer. Finally, our principle can be described as dynamic, because it can respond flexibly to changes in the structure of the network of providers. For example, if the operation of a peripheral hospital is reduced or abolished, this will quickly affect the structure of local GP activities and the attractiveness of the region for healthcare professionals, while the geographical criteria will remain unchanged. Similar analyses can be performed repeatedly at any intervals, the results can be used in planning and local policy making.

\section{CONCLUSIONS}

The combined way of dividing GP practices into urban and rural practices is based on the use of two complementary factors. The location of the practice remains the first and basic one. Equally important are the characteristics of the activity, which can be defined and compared. In our research, we focused on the performance of the practice, quantified by the total cost of the health insurance company to its policyholders. These are payments for various items, directly related to the activities of the GP practice. So they provide comprehensive information about the spectrum of its work and at the same time about the cost effectiveness of this complex activity. It seems that in the Czech Republic there is a "rural way of working" of GPs, which could be more precisely defined and used as a determinant of rural areas, especially in areas that are not clearly urban or clearly rural.

In the Czech Republic practices in rural areas and small towns provide patient care using their own resources and that is reflected in their practice equipment and staff skill 
set. They perform more procedures, make greater use of ancillary services, and issue more prescriptions, but they rely less on specialists. Results in less indicated care, saves the payer money and reduces the burden on the healthcare system. We have therefore shown that even in the small Czech Republic, regionality plays an important role in the provision of primary care.

In categorising the GP practices, we tried to follow the OECD criteria used to distinguish between three types of area (predominantly urban, intermediate, predominantly rural). We worked with different variants and ultimately obtained similar results. The key criterion is the presence of a multispecialty hospital in use with a network of related services (especially specialists) in that location. We considered the GP practices located in these areas to be typical urban ones. GP practices in the remaining areas operated efficiently (more own activities with lower total costs) regardless of whether they were categorised as intermediate or rural.

We believe that this principle of defining urban and rural GP practices is transferable and universally applicable. Although it requires knowledge of payers' cost data and a certain demographic framework, on the other hand, it can respond to changes in the network of providers (secondary and tertiary care) with a minimum of time, especially in peripheral regions. If the conditions in the provision of health services change (for example, the reduction of the activities of a peripheral hospital), it will be reflected very quickly in the activities of local GPs. It will be precisely they who will immediately be transferred to the higher demands on the range of services provided and the organization of health care.

\section{ABBREVIATIONS}

$\begin{array}{ll}\text { GP } & \text { General Practice } \\ \text { GHIC } & \text { General Health Insurance Company } \\ \text { OECD } & \begin{array}{l}\text { Organisation for Economic Co-operation and } \\ \text { Development }\end{array} \\ \text { LAU } & \begin{array}{l}\text { Local administrative unit } \\ \text { NUTS }\end{array} \\ \text { Nomenclature of Units for Territorial Statistics } \\ \text { PU } & \text { Predominantly Urban } \\ \text { IN } & \text { Intermediate } \\ \text { PR } & \text { Predominantly Rural }\end{array}$

\section{FUNDING}

No funding required for this study.

\section{ACKNOWLEDGEMENTS}

The authors' would like to thank their supervisors at Charles University for enabling them to work on this project and for their valuable comments. We would also like to thank the management of GHIC for providing the data for the research.

\section{REFERENCES}

1. Petrazzuoli F, Ungan M. Rural Medicine in theWorld (1): A Focus on Rural Primary Care in Europe, Turkiye Klinikleri J Fam Med-Special Topics 2018; 9(4): 256-61.

2. McGrail MR, Humphreys JS, Joyce CM, Scott A, Kalb G. How do rural GPs' workloads and work activities differ with community size compared with metropolitan practice? Aust J Prim Health 2012; 18(3): 228-33.

3. Montesanti S, Robinson-Vollman A, Green LA. Designing a framework for primary health care research in Canada: a scoping literature review. BMC Fam Pract 2018; 19(1): 144.

4. Liu J, Zhu B, Wu J, Mao Y. Job satisfaction, work stress, and turnover intentions among rural health workers: a cross-sectional study in 11 western provinces of China. BMC Fam Pract 2019; 20(1): 9.

5. Hart LG, Larson EH, Lishner DM. Rural definitions for health policy and research. Am J Public Health 2005; 95(7): 1149-55.

6. Sofianopoulou E, Rushton S, Rubin G, Pless-Mulloli T. Defining GP practice areas based on true service utilisation. Health Place 2012; 18(6): 1248-54.

7. de Oliveira AP, Dussault G, Craveiro I. Challenges and strategies to improve the availability and geographic accessibility of physicians in Portugal. Hum Resour Health 2017; 15(1): 24.

8. Gridley K, Spiers G, Aspinal F, Bernard S, Atkin K, Parker G. Can general practitioner commissioning deliver equity and excellence? Evidence from two studies of service improvement in the English NHS. J Health Serv Res Policy 2012; 17(2): 87-93.

9. Masseria C, Giannoni M. Equity in access to health care in Italy: a disease-based approach. Eur J Public Health 2010; 20(5): 504-10.

10. Wakerman J, Sparrow L, Thomas SL, Humphreys JS, Jones M. Equitable resourcing of primary health care in remote communities in Australia's Northern Territory: a pilot study. BMC Fam Pract 2017; 18(1): 75.

11. Gabhainn SN, Murphy AW, Kelleher C. A national general practice census: characteristics of rural general practices. Fam Pract 2001; 18(6): 622-6

12. Pohontsch NJ, Hansen H, Schäfer I, Scherer M. General practitioners' perception of being a doctor in urban vs. rural regions in Germany A focus group study. Fam Pract 2018; 35(2): 209-15.

13. Iversen L, Farmer JC, Hannaford PC. Workload pressures in rural general practice: a qualitative investigation. Scand J Prim Health Care 2002; 20(3): 139-44.

14. Kroezen M, Dussault G, Craveiro I, et al. Recruitment and retention of health professionals across Europe: a literature review and multiple case study research. Health Policy 2015; 119: 1517-28.

15. Kwan MMS, Kondalsamy-Chennakesavan S, Ranmuthugala G, Toombs MR, Nicholson GC. The rural pipeline to longer-term rural practice: General practitioners and specialists. PLoS One 2017; 12(7): e0180394.

16. Dowell J, Norbury M, Steven K, Guthrie B. Widening access to medicine may improve general practitioner recruitment in deprived and rural communities: survey of GP origins and current place of work. BMC Med Educ 2015; 15: 165.

17. Weinhold I, Gurtner S. Understanding shortages of sufficient health care in rural areas. Health Policy 2014; 118(2): 201-14.

18. Ministerstvo zdravotnictví ČR. Memorandum o vzájemné spolupráci. [Memorandum on cooperation] Available from URL: http://www.mzcr .cz/dokumenty/ministerstvo-zdravotnictvi-a-prakticti-lekari-uzavreli -memorandum-o-vzajemne-spo_15770_3801_1.html.

19. Petrovcic R. Defining rural, remote and isolated practices: the example of Slovenia. 2016. Family Medicine \& Primary Care Review 2016; 18(3): 391-393.

20. Boerma WG, Groenewegen PP, Van der Zee J. General practice in urban and rural Europe: the range of curative services. Soc Sci Med 1998; 47(4): 445-53.

21. Joumard I, Andre Ch, Nicq Ch, Health Care Systems: Efficiency and Institutions. OECD Economics Department Working Paper No. 769. 2010 May 27. Available at SSRN: https://ssrn.com/abstract $=1616546$ or http://dx.doi.org/10.2139/ssrn.1616546.

22. OECD. Health at a Glance: Europe 2018 (State od Health in the EU Cycle). https://doi.org/10.1787/health_glance_eur-2018-en. Available from URL: https://read.oecd-ilibrary.org/social-issues-migration -health/health-at-a-glance-europe-2018_health_glance_eur-2018 -en\#page133.

23. Všeobecná zdravotní pojištovna ČR. Výroční zpráva VZP ČR za rok 2016. Available from URL: https://media.vzpstatic.cz/media/Default /vyrocni-zpravy/vyrocni-zprava-vzp-2016.pdf.

24. Pracovní skupina venkovského lékařství SVL ČLS JEP. Available from URL: https://www.svl.cz/o-nas/pracovni-skupina-venkovskeho -lekarstvi-1/. 
25. OECD. Regions at a Glance, 2016. Available from URL: https://read .oecd-ilibrary.org/governance/oecd-regions-at-a-glance-2016_reg glance-2016-en\#page141.

26. OECD. Regional Typology, 2011. Available fromURL: https://www.oecd .org/cfe/regional-policy/OECD_regional_typology_Nov2012 .pdf.

27. Mehring M, Donnachie E, Schneider A, et al. Impact of regional socioeconomic variation on coordination and cost of ambulatory care: investigation of claims data from Bavaria, Germany. BMJ Open 2017; 7(10): e016218.

28. Busato A, Matter P, Künzi B, Goodman D. Geographic variation in the cost of ambulatory care in Switzerland. J Health Serv Res Policy 2012 Jan; 17(1): 18-23.

29. OECD. Health at a Glance 2017. Available from URL: https://read. oecd-ilibrary.org/social-issues-migration-health/health-at-a -glance-2017/consultations-with-doctors_health_glance-2017-60 -en\#page2.

30. OECD. Health at a Glance 2017. Available from URL: https://read. oecd-ilibrary.org/social-issues-migration-health/health-at-a -glance-2017/average-length-of-stay-in-hospitals_health_glance -2017-64-en\#page1.

31. OECD. Health at a Glance 2017. Available from URL: https://read. oecd-ilibrary.org/social-issues-migration-health/health-at-a -glance-2017/doctors-by-age-sex-and-category_health_glance -2017-53-en\#page2.

32. OECD. Regions at a Glance, 2016. Available from URL: https://read .oecd-ilibrary.org/governance/oecd-regions-at-a-glance-2016_reg glance-2016-en\#page133.

33. WHO. A System of Health Accounts, 2011 (SHA 2011). Available from URL: https://www.who.int/health-accounts/methodology/en/. 